\title{
The impact of substance misuse disorder on psychosocial aspects of patients' lives
}

\author{
Abd Alhadi Hasan* \\ Fakeeh College for Medical Sciences, Alhamra district, Palestine street, Jeddah, Saudi Arabia
}

\begin{abstract}
Background: Substance use/abuse is associated with numerous physical and social problems. These problems extend to patients and their family as well as society in general.

Aims: The aim of this study was to determine the psychosocial impact of substance use/abuse on participants.

Method: The study design was a cross-sectional survey. Purposive sampling was used and 181 male participants were recruited at the Al-Amal Hospital in Jeddah in April and May, 2017. A self-administration questionnaire was used.

Results: $50.8 \%(\mathrm{n}=92)$ of the study participants were aged $20-29$ years and $22.1 \%(\mathrm{n}=40)$ were in the age group $30-39$ years. $15.4 \%$ ( $=28)$ of the participants had been addicted for six years or more and $57.4 \%(n=104$ for 1 to 3 years. The most commonly used substances were amphetamines, alcohol and marijuana. The greatest effect was on self-esteem, followed by anxiety, depression, hostility and risk taking. Interestingly, group one (alcohol) and group three (amphetamine) showed the highest psychosocial influence.
\end{abstract}

Conclusions: Substance use/abuse significantly affected psychosocial aspects, especially self-esteem and depression.

\section{Background}

Addiction is defined as a primary, chronic disease of brain reward motivation, memory and related circuitry [1]. Dysfunction in these circuits leads to characteristic biological, psychological, social and spiritual manifestations reflected in an individual pathologically pursuing reward and/or relief by substance use and other behaviours [2]. One of the most common features of addiction is that the patient lacks the ability to steadily withdraw from the addictive substance, impairment in behavioural control, craving, diminished recognition of significant problems in one's behaviour and interpersonal relationships, and dysfunctional emotional responses [3]

Mallorquí-Bagué, et al. [4] report that illicit drug use can cause thinking, performance and learning process problems. Moreover, drugs have a severe impact on the psychological status; they can cause severe stress and inability to perform of daily activities. Substances like heroin and cocaine can cause chemical dependence, which strongly affect the brain [5]. Overall, drug addiction can cause depression, mood disturbance, insomnia, anorexia, sexual dysfunction, paranoia and hallucination [2]. During the early stage of addiction, a person may use these substances to seek pleasure. However, this feeling requires ever higher doses to get the same effect. This, in turn, contributes an increased likelihood of serious side effects/complications, with an increased risk of death [6,7]. The average number of heroin users increased from 1.6 per 1,000 in 2002 to 2.6 per 1,000 in 2013. Amphetamines also have psychosocial influences on the individual, such as nervousness, insomnia, weight loss, aggression, anxiety, and disturbance of mood. Another common substance which has a negative psychosocial impact is cannabis, which induces amnesia, bronchial irritation, delay in movement, lethargy, lack of motivation, and disturbance of mood and behaviour [6]. Poudel, et al. [8] found that $43 \%$ of adults in the US used cannabis, $13 \%$ recurrently.

Ali [9] concluded that drug addiction not only influences the patient but also affects the relationship with family members. This, in turn, leads to loss of security, and isolation. In terms of the impact on the family, substance misuse causes a breakdown in relationships and is associated with partner violence [10]. This finding is echoed by $T$ Nordfjærn [11], who compared the impact of high and low consumption of illicit drugs and alcohol on psychological distress and interpersonal relationships in Norway. The study employed a cross-sectional approach with 352 patients ( $70 \%$ male vs. $30 \%$ female). The researcher used self-administration questionnaires: drug abuse screening test (DAST-20), alcohol use disorders identification test (AUDIT) and multidimensional symptoms checklist-90-revised (SCL90-R) to assess psychological distress for individuals, and circumplex of interpersonal problems (CIP). The study found that the most common illicit drugs were opioids; high doses of illicit drugs were expressed in negative psychosocial status, as indicated by depression, hostilityanger, and somatization. However, the level of alcohol consumption was statistically significantly correlated with the perceived anxiety level and obsessive-compulsive disorders. In terms of interpersonal problems, the results indicated that high consumption of alcohol results

*Correspondence to: Abd Alhadi Hasan, Fakeeh College for Medical Sciences, Alhamra district, Palestine street, Jeddah, Saudi Arabia, Fax: 009665476543216, Tel: 00966536406602; E-mail: aalhasan@fakeeh.care

Key words: psychosocial, substance misuse, physical and social problems

Received: February 12, 2019; Accepted: February 19, 2019; Published: February 25,2019 
in intrusive behaviour, and illicit drug use in vindictive behaviour towards others. It has been demonstrated that negative life events are a precipitating factor in the use of illicit drugs and alcohol, leading to erosion of self-efficacy and interpersonal problems [12].

Alinsaif [13] conducted a cross-sectional study in Saudi Arabia's eastern region, aimed at exploring the psychosocial factors leading to the use of alcohol. The author recruited 120 participants aged 18 to 69 from Saudi Narcotics Anonymous and the Al-Amal complex in the eastern region. A self-reported questionnaire was administered to assess psychosocial factors among participants. Interestingly, the result showed that $32.7 \%$ of participants attributed peer pressure as the main reason for their addiction, even though a majority had never experienced child abuse or a family history of drinking problems. Importantly, the most common psychological factor that led participants to use alcohol (22.5\%) was a feeling of happiness after consumption; for the personality factor, $32 \%$ of participants reported that they were seeking sensation; and for the social factor, $35 \%$ of participants reported that the influence of family was the strongest reason for using alcohol. From my perspective, there is controversy in the results: the author claimed that $70.3 \%$ of the participants had no family history of alcohol drinking, although concluding that $35 \%$ gave imitating family members as a reason for using alcohol.

At the same line, Hassel, et al. [3] conducted a study to investigate the psychological and interpersonal distress among patients with substance use disorders. The sample comprised 346 participants from 16 different treatment centres in Norway. The researchers were used the self-administration questionnaire CIP and the general perceived self-efficacy scale (GES). Psychological distress was measured by SCL-90-R, and alcohol consumption by AUDIT and DAST-20. There was a positive correlation between age and substance abuse, but no correlation between gender and substance abuse. The results of the study also showed that substance use disorder had a negative influence on psychological and interpersonal problems. Furthermore, the relationship between anxiety, somatization and concentration strongly accompanied both illicit substance use and alcohol consumption. Anger, vulnerability, suspiciousness and psychoticism were associated with illicit substance use.

Armstrong, et al. [14] measured the quality of life, depression, anxiety and suicidal ideation among males who used an injection form of heroin, marihuana and diazepam in Delhi, India. The study design was a cross-sectional survey with 420 participants. The results of the study indicated that $76 \%$ of the sample used heroin, $73 \%$ used marijuana and $53 \%$ were addicted to diazepam. More than half of the sample experienced suicidal ideation during the past 12 months and $36 \%$ of participants had made at least one attempt to commit suicide. In terms of depression and anxiety, the results showed that $84 \%$ of individuals lived with depression and $54 \%$ with anxiety. The study concluded that there was a high rate of depression, anxiety and suicidal ideation among participants as a result of the unmet requirements for mental healthcare in India.

A study conducted in Italy by Tiziana, et al. [15] explored the relationship between substance use disorders and severe psychiatric disorder. The brief psychiatric rating scale (BPRS), global assessment of functioning scale (GAF) and clinical global impression-severity (CGI-S) were used to assess psychiatric symptoms. The 848 participants were classified by an active or negative substance use disorder according to their consumption over the past six months. The results revealed that people who had an active status experienced more frequent psychiatric problems such as personality disorder cluster B (53\%) than cluster A
(11.36\%) or C (35.23\%). Another psychiatric disorder predominant among active patients was depression. The key problem with the findings of this study is that socio-demographic characteristics, psychiatric history and clinical status were not recorded. In addition, BPRS is not as sensitive an indicator of psychiatric symptoms as the positive and negative syndrome scale (PANSS)

Arteaga, et al. [16] found that $33 \%$ of individuals with drug addiction $(\mathrm{n}=162)$ had a history of intimate partner violence (IPV). The authors compared those with IPV $(n=70)$ and those without IPV $(n=92)$. As expected, individuals with IPV reported significantly higher scores for aggressive, negativistic, paranoid and delusion disorders. Alcohol and cocaine users commonly experienced antisocial behaviour. There were several forms of violence to which partners were exposed: physical violence was prevalent $(n=65)$, followed by psychological violence ( $n$ $=42)$, with sexual violence last $(\mathrm{n}=17)$.

The study conducted by H. Alzahrani, et al. [17] in Saudi Arabia, examined depression and associated factors among patients with substance use disorders, using a quantitative cross-sectional study with 165 participants. The Arabic version of the Beck depression inventory (BDI) was used to assess the depression level. The study emphasized other studies in which the majority of participants used amphetamines (72.2\%). In addition, a higher proportion consumed dual substances (74.5\%) and $40 \%$ more than two types of substance. Overall $95.2 \%$ of participants reported a severe level of depression. Another interesting finding is that people addicted to heroin reported a higher level of depression than amphetamine users (100\% vs $80 \%)$. Furthermore, the intensity of psychological distress was found to depend on the duration of consuming a substance rather than the number of substances used.

In Al Baha Psychiatric Hospital in Saudi Arabia, Youssef, et al. [18] compared 122 participants addicted to more than one type of substances with a control group of 117 participants who had never used illicit drugs and had no history of psychiatric illness in terms of a history of suicidal thought or attempt. Amphetamines were the most commonly used drugs ( $87 \%)$, followed by cannabis $(70 \%)$ and alcohol (37\%). These results suggested that alcohol, amphetamines and volatile substances were associated with frequent suicidal thoughts. One striking finding of this study was that there was no link between the age of starting substance use and suicidal thoughts, although the duration of substance use was an important factor in suicidal thought and attempts. Depression and a higher likelihood of suicide were frequently observed as a result of substance abuse. There was a strong relationship between suicidal thoughts or attempts and using more than one substance.

In Amman, Al Ghaferi, et al. [19] conducted a study to test the effectiveness of the bio-psychosocial and spiritual model in treating addiction, using semi-structured interviews with 25 participants. The interview questions were related to the initiation of substance use, increased use and dependence, health effects of addiction, spiritual and social consequences of addiction, and looking for treatment. The participants declared that they suffered unpleasant physical withdrawal symptoms such as sweating, headache, pain and diarrhea. As for the psychological aspects, mood-related disorder was prioritized. At the social level, family dysfunction and breakdown of marital relationships was noticed.

Although the studies reviewed here found that substances have a negative impact on the psychosocial life of patients, there is diversity in the reported results. Most of these studies used an ad hoc instrument. Overall, the researchers noted an under-representation of female 
patients. It was also observed that the studies had a common tendency to recruit patients addicted to alcohol. This is the first study that has used validated outcome measures on patients diagnosed with substance disorder worldwide and designed specifically to measure psychosocial aspects. Furthermore, most studies were carried out in the West, with few countries from the developing world. To date, only a limited number of studies have investigated the impact of substance groups on psychosocial aspects. Evidence from these studies cannot be directly transferred to the Saudi healthcare system without examination of some contextual factors including variations in healthcare systems and culture. To draw definitive conclusions, a well-designed cross-sectional study, adequately powered, is needed to identify the psychosocial impact of substance groups.

Overall, the findings of this literature review reported a wide range of outcome measures, making it impossible to compare the results. In addition, as noted earlier, most of the studies were inappropriate to detect the psychosocial effects of substance use/abuse. The purpose of the present study was therefore to examine the impact of substance consumption on the psychosocial aspects of patients' life.

\section{Methods}

\section{Research Design}

The study employed a descriptive explanatory correlation design.

\section{Setting}

The present study was carried out in the Al-Amal Mental Health Government Hospital in Jeddah. The hospital consists of eight wards (six male and two female) caring for 231 patients. The hospital's total capacity is 125 beds (six in the ER ward and 119 in the male and female in-patient wards). The reason for choosing this setting is the availability of patients with a history of addiction; the hospital serves the majority of patients who have substance misuse disorder and it was easily accessible by the researcher.

\section{Participants and Outcome Measures}

The study was carried out on a convenience purposive sample of 181 . The response rate was $92 \%$. Data were collected through a self-administered structured questionnaire, which aimed to assess the psychosocial impact of substance abuse on patients' lives. It has two parts: the first comprised items concerning socio-demographic characteristics and the second part included outcomes of interest.

\section{Psychosocial and Social Functioning}

Psychosocial and Social Functioning Scale: The Psychosocial and Social Functioning Scale adopted in the current study was developed by Knight and Simpson (1994). From the original 83 items distributed over eight domains, 56 items were chosen for the current study. The eight subscales focus on two main categories: psychological scales (self-esteem 6 items, depression 6 items, anxiety 7 items and decision making, confidence 7 items); and social scales (childhood problems 8 items, hostility 8 items, risk taking 7 items, and social conformity 7 items). A five-point Likert scale was used, with total possible scores ranging from 56 to 280; where higher scores indicate a higher rank on both psychological and social dimensions after reversing some items. The translated version of the outcome measures showed good reliability, indicated by a coefficient value for the total score of 0.77 .

Ethical considerations: Verbal and written consent was sought from the participants after clarifying the procedure. Participants were informed about their right to refuse to participate and to withdraw at any time without any consequences. Confidentiality was assured. Ethical approval was obtained from the Fakeeh College for Medical Sciences (ref: 164126/45) and from the Ministry of Health (ref 17845/67).

\section{Statistical Analysis}

Descriptive statistics were used to summarize baseline characteristics, including socio-demographic and clinical information. For the current study, substances were classified as follows: group one alcohol; group two marijuana; group three amphetamine; and group four mixed involving sedative, pain-killer and methadone. One-way analysis of variance test was employed to test the impact of substance groups on psychosocial aspects. In respect to multi-comparison tests to guard against wrongly rejecting a null hypothesis and type 1 error, the adjustment level of significance was performed. The adjusted level of significance set as baseline for all statistical tests was thus determined at the $1 \%$ level $(\mathrm{p}<0.05)[20-22]$.

\section{Results}

A total of 205 patients were recruited in the period March to May 2018. However, 17 refused to cooperate or to follow the study directions, and seven were excluded as they did not respond to the research team's contact. The sample size was calculated to detect correlation between variables with a medium effect size at 0.80 power, level of significance of 0.05 [23]. Participants received either hard or soft copies of the outcome measures. Phone and email messages were sent to all participants reminding them to complete the study questionnaire.

Table 1 summarizes the demographic background of the participants. All of the final 181 participants were male; the largest age group was 20 to $29(50.8 \%)$ and $46.9 \%$ had primary level education.

\section{Drug Type}

The results showed that amphetamine was the most common drug used among participants, at $46.4 \%(\mathrm{n}=33)$. Marijuana was second at $57.7 \%(\mathrm{n}=41)$, followed by alcohol $14.1 \%(\mathrm{n}=14)$. The group of "mixed" drugs was the smallest, at $11.20 \%$. Table 2 presents the frequencies and percentages of the used substances. (Table 2)

\section{Substance impacts on the psychological and social factors of the patient's life}

One-way ANOVA test was employed to compare the psychosocial aspects between the groups. Interestingly, self-esteem was observed to be strongly affected by all substances, although it was highest in group three, amphetamine $($ mean $=3.85)$. However, depression and anxiety scores were prevalent in groups two and three (cannabis and/ or amphetamine). It is also apparent from these ANOVA results that alcohol (group one) has a more direct influence on decision making than the other substances. The most surprising aspect of the data is that people addicted to alcohol had relatively higher scores for hostility. As expected, risk taking was higher among alcohol and amphetamine abusers. In terms of social conformity, the data showed that alcohol abusers had higher scores in this domain (mean 3.51) compared with the remaining substances. The results of the ANOVA test are illustrated in Table 3.

Between/within groups ANOVA test was used to examine the psychosocial impact of each substance. The mean difference for selfesteem was statistically significant between substances $(p=0.007)$. 
Table 1. Characteristics of the Study Participants

\begin{tabular}{|c|c|}
\hline Variable & $\%(n)$ \\
\hline \multicolumn{2}{|l|}{ Age } \\
\hline $20-29$ years & $50.8 \%(92)$ \\
\hline $30-39$ years & $22.1 \%(40)$ \\
\hline $40-49$ years & $15.4 \%(28)$ \\
\hline 50 years and above & $17.1 \%(31)$ \\
\hline \multicolumn{2}{|l|}{ Education Level } \\
\hline Primary & $46.9 \%(85)$ \\
\hline Intermediate & $8.2 \%(15)$ \\
\hline Secondary & $24.8 \%(45)$ \\
\hline Diploma & $8.2 \%(15)$ \\
\hline University & $11.6 \%(21)$ \\
\hline \multicolumn{2}{|l|}{ Occupation } \\
\hline Governmental & $60.7 \%(110)$ \\
\hline Military & $28.7 \%(52)$ \\
\hline Private & $9.9 \%(18)$ \\
\hline Free Business & $2.7 \%(5)$ \\
\hline Unemployed & $2.7 \%(5)$ \\
\hline \multicolumn{2}{|l|}{ Monthly income } \\
\hline $3000 \mathrm{SR}$ or less & $75.1 \%(136)$ \\
\hline $3000-6000$ & $11.4 \%(20)$ \\
\hline $6000-10000$ & $9.3 \%(17)$ \\
\hline $10000-15000$ & $1.6 \%(3)$ \\
\hline 15000 and above & $2.7 \%(5)$ \\
\hline \multicolumn{2}{|l|}{ Marital status } \\
\hline Single & $70.1 \%(127)$ \\
\hline Married & $18.2 \%(33)$ \\
\hline Divorced & $11.6 \%(21)$ \\
\hline \multicolumn{2}{|l|}{ Number of family members } \\
\hline Less than 5 members & $53.0 \%(96)$ \\
\hline 5 - 9 members & $35.9 \%(65)$ \\
\hline 10 members and above & $11.0 \%(20)$ \\
\hline \multicolumn{2}{|l|}{ Year of drugs addiction } \\
\hline $1-3 y r s$ & $18.2 \%(33)$ \\
\hline 3-6yrs & $24.3 \%(44)$ \\
\hline 6 yrs and above & $57.4 \%(104)$ \\
\hline \multicolumn{2}{|l|}{ Family Disease history } \\
\hline No family history & $77.3 \%(140)$ \\
\hline Addiction & $11.6 \%(21)$ \\
\hline Psychiatric disease & $11.0 \%(20)$ \\
\hline \multicolumn{2}{|l|}{ How did you start drug use } \\
\hline Friends impact & $39.7 \%(72)$ \\
\hline Curiosity & $21.5 \%(39)$ \\
\hline During travelling & $11.0 \%(20)$ \\
\hline Waste time & $3.3 \%(6)$ \\
\hline Imitation & $1.1 \%(2)$ \\
\hline Abundance of money & $6.6 \%(12)$ \\
\hline Social problems & $9.9 \%(18)$ \\
\hline Weakness of religious faith & $6.0 \%(11)$ \\
\hline All & $4.9 \%(9)$ \\
\hline \multicolumn{2}{|c|}{ I have a passion or very strong desire to drink alcohol or drugs } \\
\hline No & $55.8 \%(101)$ \\
\hline Yes & $44.1 \%(80)$ \\
\hline \multicolumn{2}{|l|}{$\begin{array}{l}\text { I have a desire to drink more alcohol and } \\
\text { drugs to reach the desired effect }\end{array}$} \\
\hline No & $52.4 \%(95)$ \\
\hline Yes & $47.6 \%(86)$ \\
\hline \multicolumn{2}{|l|}{ The main addicted drug in the last year } \\
\hline Group one (Alcohol) & $11.6 \%(21)$ \\
\hline Group two (Marijuana) & $25.4 \%(46)$ \\
\hline Group three (amphetamine) & $53.0 \%(96)$ \\
\hline Group four mixed (sedative, pain-killers...etc) & $9.9 \%(18)$ \\
\hline
\end{tabular}

Table 2. Frequencies and percentages of the drug used among the study sample

\begin{tabular}{|l|l|}
\hline The main addicted drug in the last year & Percentages \\
\hline Group one (Alcohol) & $19.7 \%(36)$ \\
\hline Group two (Marijuana) & $22 \% .5(40)$ \\
\hline Group three (amphetamine) & $47.5 \%(86)$ \\
\hline Group four mixed (sedative, pain-killers...etc) & $10.4 \%(19)$ \\
\hline
\end{tabular}

Moreover, the means for anxiety and depression varied significantly between groups $(\mathrm{p}=0.001)$, with cannabis (group two) () having the strongest effect. Alcohol's impact on decision making, social conformity and hostility domains is statistically more significant than other substances $(\mathrm{p}<0.05)$. Cannabis showed more influence on childhood problems $(\mathrm{p}=0.03)$. Table 4 compares the impact of the substance groups on psychosocial domains.

Post hoc comparisons using the honest significant difference (HSD) test to evaluate the pairwise mean differences of each domain indicated significant differences between the groups at the $5 \%$ level of significance (to protect against type 1 error); this showed that alcohol and amphetamine more impact on the self-esteem domain compared with other substances; alcohol (mean difference: 0.28, SE 0.14: $\mathrm{p}<0.005$ ) and amphetamine (mean difference: 0.52, SE 0.20, $\mathrm{p}<0.05$ ). Furthermore, the post hoc result on depression scores indicated that three groups had equal impact on the depression factor, which was statistically significant when compared with group four; specifically: differences between group one and group four (mean difference: 0.78 , $\mathrm{SE} 0.25, \mathrm{p}<0.05$ ), group two and group four (mean difference: 0.83 , SE 2.3, $\mathrm{p}<0.05$ ) as well as between group three and group four (mean difference: 0.85 , SE $0.20, \mathrm{p}<0.001$ ).

The results of the post hoc test regarding anxiety showed that cannabis (group two) had a greater effect on anxiety than the other groups: the mean difference between group two and group one in relation to anxiety is (mean difference 0.91, SE 0.34, $\mathrm{p}<0.05$ ), group three (mean difference 0.56 , SE $0.25, \mathrm{p}<0.05$ ) and mixed group (mean difference 1.32, SE 0.32, $\mathrm{p}<0.05$ ). There was also a significant difference in relation to the impact of group one (alcohol) on decision making between groups. This difference was highly significant statistically in group three (mean difference: 0.66 , SE $0.18, \mathrm{p}<0.01$ ), group two (mean difference: $0.51, \mathrm{SE} 0.18, \mathrm{p}<0.05$ ) and group four (mean difference; 0.59 , SE 0.22, $\mathrm{p}<0.05)$.

Further statistical tests revealed that group two (cannabis) and group three (amphetamine) demonstrated more influence on childhood problems. This was evident from the wide mean difference between groups two and one (mean difference 0.75, SE 0.26, $\mathrm{p}<0.01$ ) and between groups three and one (mean difference 0.65, SE 0.24, $\mathrm{p}<0.01$ ). Interestingly, group one (alcohol) showed more impact on hostility, indicated by significant mean difference in comparison to group two (mean difference: $0.72, \mathrm{SE} ; 0.30, \mathrm{p}<0.05$ ) and group three (mean difference: 0.53 , SE; $0.27, \mathrm{p}<0.05$ ). In the same vein, group one showed higher impact on risk taking in comparison to group two (mean difference: 0.83, SE; $0.24, \mathrm{p}<0.01$ ) and group three (mean difference: 0.32 , SE; $0.21, \mathrm{p}<0.01$ ) and the mixed group (mean difference: $0.74, \mathrm{SE}$; $0.26, \mathrm{p}<0.01$ ). The findings also showed statistically greater significant differences in social conformity for group one, compared with the other groups, specifically the difference with group two (mean difference: 0.64 , SE; 0.12, $\mathrm{p}<0.001$ ), group three (mean difference: 0.68 , SE; 0.11, $\mathrm{p}<0.001$ ) and group four (mean difference: 0.64 ; SE; $0.13, \mathrm{p}<0.001$ ). The data is shown in Table 5.

Spearman correlation test was administered to examine the relationship between socio-demographic variables and psychosocial domains. It appears that education level has a positive correlation with 
Hasan AA (2019) The impact of substance misuse disorder on psychosocial aspects of patients' lives

Table 3. Means and Standard deviation of psychosocial domains

\begin{tabular}{|c|c|c|c|c|c|c|c|c|}
\hline \multirow{2}{*}{ Domain } & \multicolumn{2}{|c|}{ Group one } & \multicolumn{2}{|c|}{ Group two } & \multicolumn{2}{|c|}{ Group three } & \multicolumn{2}{|c|}{ Group four } \\
\hline & Mean & SD & Mean & SD & Mean & SD & Mean & SD \\
\hline Self esteem & 3.83 & 0.49 & 3.57 & 0.66 & 3.85 & 0.39 & 3.31 & 0.36 \\
\hline Depression & 2.95 & 0.60 & 3.58 & 0.79 & 3.46 & 0.45 & 2.70 & 0.84 \\
\hline Anxiety & 2.73 & 0.86 & 3.64 & 0.56 & 3.28 & 0.97 & 2.32 & 0.75 \\
\hline Decision Making & 3.21 & 0.62 & 2.70 & 0.54 & 2.55 & 0.45 & 2.62 & 0.51 \\
\hline Childhood problems & 2.29 & 0.76 & 3.04 & 0.70 & 2.94 & 0.57 & 2.86 & 0.75 \\
\hline Hostility & 3.64 & 0.37 & 2.91 & 0.90 & 3.10 & 0.76 & 2.56 & 0.81 \\
\hline Risk Taking & 3.70 & 0.21 & 2.86 & 0.84 & 3.37 & 0.47 & 2.95 & 0.77 \\
\hline Social conformity & 3.51 & 0.46 & 2.86 & 0.33 & 2.82 & 0.29 & 2.86 & 0.22 \\
\hline
\end{tabular}

Table 4. ANOVA test for the differences in psychological and social domains according to substance types

\begin{tabular}{|c|c|c|c|c|c|c|}
\hline Domain & Group & Sum of squares & Df & Mean square & $\mathbf{F}$ & Sig. \\
\hline Self esteem & $\begin{array}{l}\text { Between groups } \\
\text { Within groups }\end{array}$ & $\begin{array}{c}2.97 \\
15.30\end{array}$ & $\begin{array}{l}3 \\
67\end{array}$ & $\begin{array}{l}0.99 \\
0.22\end{array}$ & 4.34 & 0.007 \\
\hline Depression & $\begin{array}{l}\text { Between groups } \\
\text { Within groups }\end{array}$ & $\begin{array}{c}6.98 \\
24.58\end{array}$ & $\begin{array}{c}3 \\
67\end{array}$ & $\begin{array}{l}2.33 \\
0.36\end{array}$ & 6.34 & 0.001 \\
\hline Anxiety & $\begin{array}{l}\text { Between groups } \\
\text { Within groups }\end{array}$ & $\begin{array}{l}13.15 \\
48.08\end{array}$ & $\begin{array}{c}3 \\
67\end{array}$ & $\begin{array}{l}4.38 \\
0.71\end{array}$ & 6.10 & 0.001 \\
\hline Decision Making & $\begin{array}{l}\text { Between groups } \\
\text { Within groups }\end{array}$ & $\begin{array}{c}3.49 \\
17.78\end{array}$ & $\begin{array}{l}3 \\
67\end{array}$ & $\begin{array}{l}1.16 \\
0.26\end{array}$ & 4.38 & 0.007 \\
\hline Childhood problems & $\begin{array}{l}\text { Between groups } \\
\text { Within groups }\end{array}$ & $\begin{array}{c}4.09 \\
29.65\end{array}$ & $\begin{array}{c}3 \\
67\end{array}$ & $\begin{array}{l}1.36 \\
0.44\end{array}$ & 3.08 & 0.03 \\
\hline Hostility & $\begin{array}{l}\text { Between groups } \\
\text { Within groups }\end{array}$ & $\begin{array}{c}6.70 \\
39.40\end{array}$ & $\begin{array}{l}3 \\
67\end{array}$ & $\begin{array}{l}2.23 \\
0.58\end{array}$ & 3.79 & 0.01 \\
\hline Risk Taking & $\begin{array}{l}\text { Between groups } \\
\text { Within groups }\end{array}$ & $\begin{array}{c}5.93 \\
24.84\end{array}$ & $\begin{array}{l}3 \\
67\end{array}$ & $\begin{array}{l}1.97 \\
0.37\end{array}$ & 5.33 & 0.002 \\
\hline Social conformity & $\begin{array}{l}\text { Between groups } \\
\text { Within groups }\end{array}$ & $\begin{array}{l}3.87 \\
6.88\end{array}$ & $\begin{array}{c}3 \\
67\end{array}$ & $\begin{array}{l}1.29 \\
0.10\end{array}$ & 12.57 & 0.000 \\
\hline
\end{tabular}

Table 5. Results of Tukey Honest pairwise comparisons of substance groups impact on psychosocial

\begin{tabular}{|c|c|c|c|c|c|}
\hline \multirow[b]{2}{*}{ Domain } & \multirow[b]{2}{*}{ Substance group } & \multicolumn{4}{|c|}{ Mean difference } \\
\hline & & Group one & Group two & Group three & Group four \\
\hline \multirow{4}{*}{ Self esteem } & Group one & & 0.26 & -.014 & 0.52 \\
\hline & Group two & -0.26 & & -0.28 & 0.25 \\
\hline & Group three & 0.014 & 0.280 & & 0.53 \\
\hline & Group four & -0.52 & -0.254 & -0.53 & \\
\hline \multirow{4}{*}{ Depression } & Group one & & -0.052 & -0.067 & 0.78 \\
\hline & Group two & 0.052 & & -0.015 & 0.83 \\
\hline & Group three & 0.067 & 0.015 & & 0.85 \\
\hline & Group four & -0.78 & -0.83 & -0.850 & \\
\hline \multirow{4}{*}{ Anxiety } & Group one & & -0.91 & -0.357 & 0.408 \\
\hline & Group two & 0.91 & & 0.561 & 1.327 \\
\hline & Group three & 0.35 & -0.56 & & 0.765 \\
\hline & Group four & -0.40 & -1.32 & -0.765 & \\
\hline \multirow{4}{*}{ Decision Making } & Group one & & 0.51 & 0.66 & 0.59 \\
\hline & Group two & -0.51 & & 0.15 & 0.07 \\
\hline & Group three & -0.60 & -0.15 & & -0.15 \\
\hline & Group four & -0.59 & -0.07 & 0.078 & \\
\hline \multirow{4}{*}{ Childhood problems } & Group one & & -0.75 & -0.65 & -0.52 \\
\hline & Group two & 0.75 & & 0.099 & 0.23 \\
\hline & Group three & 0.65 & -0.09 & & 0.13 \\
\hline & Group four & 0.524 & -0.23 & -0.13 & \\
\hline \multirow{4}{*}{ Hostility } & Group one & & 0.72 & 0.53 & 1.07 \\
\hline & Group two & -0.72 & & -0.18 & 0.35 \\
\hline & Group three & -0.53 & 0.18 & & 0.54 \\
\hline & Group four & -1.075 & -0.35 & -0.54 & \\
\hline \multirow{8}{*}{ Risk Taking } & Group one & & 0.83 & 0.32 & 0.748 \\
\hline & Group two & -0.83 & & -0.50 & -0.08 \\
\hline & Group three & -0.32 & 0.50 & & 0.422 \\
\hline & Group four & -0.74 & 0.084 & -0.42 & \\
\hline & Group one & & 0.646 & 0.688 & 0.648 \\
\hline & Group two & -0.64 & & 0.041 & 0.001 \\
\hline & Group three & -0.68 & -0.041 & & -0.039 \\
\hline & Group four & -0.64 & -0.001 & 0.039 & \\
\hline
\end{tabular}


self-esteem $(r=0.25, \mathrm{p}<0.05)$ and income $(\mathrm{r}=0.26$, $\mathrm{p}<0.05)$. However, illness duration was significantly negatively correlated with self-esteem $(\mathrm{r}=-0.23, \mathrm{p}<0.05)$. The analysis showed a significant negative correlation between decision making and marital status $(r=-0.28, p<0.05)$, income $(\mathrm{r}=-0.62, \mathrm{p}<0.05)$ and family history $(\mathrm{r}=-0.48, \mathrm{p}<0.05)$. Furthermore, there was a significant negative correlation between risk taking and age $(r=-0.25, p<0.05)$ as well as social conformity and age $(r=-0.18$, $\mathrm{p}<0.05)$ beside illness duration $(\mathrm{r}=-0.34, \mathrm{p}<0.05)$. However, age is positively correlated with hostility $(\mathrm{r}=0.14, \mathrm{p}<0.05)$. The results of the correlation analysis are summarized in Table 6.

\section{Discussion}

The present study showed that group two (marijuana) and group three (amphetamine) had a higher impact on anxiety and depression; this finding is consistent with those of Bolton, et al. [24], who demonstrated that using illicit drugs to relieve symptoms of depression or stressors was widely spread between people [5]. Similarly, AlKandari, et al. [25] illustrated marijuana had a three times greater impact on depression and anxiety than alcohol and heroin, although this was because the majority of their participants were addicted to alcohol and heroin. This result also confirms the finding of Al-Zahrani, et al. [17], that depression was linked with amphetamine use/abuse.

In this study, self-esteem was found to be affected more by alcohol and amphetamine than the other substances. This finding is in line with the study of Kavas [26], who found a relationship between selfesteem and amphetamine use/abuse. This suggests that self-esteem is a key factor in the prevention of substance misuse, and participants should be encouraged to use available resources when handling challenging situations. It can therefore be assumed that self-esteem enhances individual capability to make irrational choices and/or actions. Interestingly, this was reflected in the hostility domain where it was apparent that people addicted to group one and group three substances had a higher tendency to aggression towards themselves or others (hostility). Hostility was linked with both alcohol and amphetamine. This might be explained by the fact that amphetamine produces grandiosity accompanied by aggressive behaviour; and when individuals cease drinking their withdrawal symptoms include aggression. Ali [9] concluded that childhood problems were a significant predictor for substance use disorder.

Furthermore, it has been found that self-esteem has both direct and indirect impacts on psychosocial domains such as depression and relationship with others. This indicates that self-esteem reflects the power of self-control and/or self-efficacy when facing any challenge. Few studies measured this psychosocial aspect. However, in a similar context the relationship between positive and negative life events and self-efficacy on psychological distress was examined. The study concluded that negative life events cause substance use disorder and psychological distress; conversely, self-efficacy and positive life events were negatively correlated with substance use.
As regards childhood problems, the results indicated that marijuana and amphetamine are associated with this domain. While family intimacy and a positive relationship can direct children to make good decisions, children who face neglect or abuse from their family or society may take to substance use/abuse. This finding is consistent with the results of Ali [9]. The risk-taking domain has a significant relationship with both alcohol and amphetamine; male adolescents are more often involved in risky and unhealthy activities, reflected in their desire to obtain substances through wrong or dangerous practice. It can also be explained by the mechanism by which substances or drugs work on the brain and affect the functional tasks and chemical balance that play a role in thinking and situation analysis. In terms of social conformity, Al-Kandari, et al. [25] and Al Ghaferi, et al. [19] confirmed our study findings and stated that people addicted to alcohol had family dysfunction and poor inter-personal relationships. In addition, the decision-making domain is strongly linked with alcohol. Further research in this domain is needed, to compare this domain and alcohol consumption.

To the best of our knowledge, this is the first study to examine the psychosocial impact of the four substance groups. The fact that participants were recruited from the largest psychiatric clinic in Jeddah strengthens the results of observational studies in epidemiology used to assess the quality of the study report. Although this study is rated as of good quality, it has several limitations. First, all the study sample were males, so the impact of substance groups on female patients cannot be discussed. This could be explained by cultural factors. Further study needs to be conducted to include female patients diagnosed with substance use disorders. Second, calculations revealed that 108 participants are needed as a viable sample; however, the time constraint of the masters programme was a barrier to recruiting a larger number. Third, the current study was planned to include participants from the Al-Amal Hospital in Riyadh but delay in receiving ethical approval from the Ministry of Health forced us to recruit participants from only the Jeddah hospital.

The clinical implication of the study is the need to integrate the biological, psychological and social components of treatment plans for substance misuse disorder. The prevailing biomedical paradigm is inadequate in dealing fully with the withdrawal symptoms associated with substance misuse disorder, and indeed the complex needs of people with mental illness in general. This study strongly endorses the need to expand service provision in psychiatric clinics to consider social and psychological aspects in the treatment. It is crucial to engage family members in the management of patients, because they can add knowledge about how to handle particular situations.

\section{Conclusion}

This study examined drug abuse in individuals and how the different types of drug can affect their lives at different stages. Treatment for addicts should therefore not be limited to the intoxication phase but

Table 6. Bivariate correlation between psychosocial domains and socio-demographic variables (Spearman coefficient)

\begin{tabular}{|c|c|c|c|c|c|c|c|c|}
\hline & Self esteem & Depression & Anxiety & $\begin{array}{l}\text { Decision } \\
\text { Making }\end{array}$ & $\begin{array}{l}\text { Childhood } \\
\text { problem }\end{array}$ & Hostility & Risk-taking & Social conformity \\
\hline Age & -0.05 & 0.71 & -0.27 & 0.07 & -0.29 & $0.14^{*}$ & $-0.25^{*}$ & $-0.17^{*}$ \\
\hline Education level & $0.25^{*}$ & 0.12 & 0.17 & -0.27 & 0.19 & 0.30 & $0.42^{*}$ & 0.36 \\
\hline Employment setting & -0.15 & 0.11 & 0.08 & 0.22 & 0.18 & 0.35 & 0.42 & 0.52 \\
\hline Marital status & -0.02 & -0.17 & -0.12 & $-0.28^{*}$ & 0.51 & 0.47 & 0.19 & 0.33 \\
\hline Income & $0.26^{*}$ & -0.11 & 0.12 & $-0.62^{*}$ & -0.38 & -0.29 & -0.53 & -0.47 \\
\hline Illness duration & $-0.23^{*}$ & 0.12 & -0.09 & $0.28^{*}$ & -0.39 & -0.26 & -0.19 & $-0.34^{k}$ \\
\hline Family history & -0.12 & -0.05 & 0.05 & -0.48 & -0.58 & -0.46 & -0.39 & -0.64 \\
\hline
\end{tabular}


should engage with patients in a holistic manner; helping them to solve the problems related to their addiction is a major role of the nursing and other medical teams. This study helps us as nurses to understand the problems in this area of practice that may face addicts, concerning their physical, social, emotional, psychological and spiritual health. Self-esteem, depression and anxiety are the most common aspects affected by the various forms of substance use/abuse.

\section{References}

1. Galvani S (2015) 'Drugs and Relationships Don't Work': Children's and Young People's Views of Substance Use and Intimate Relationships. Child abuse review 24 440-451.

2. Mohr WK, Mohr WK (2013) Psychiatric Mental Health Nursing: Evidence-based Concepts, Skills, and Practices: Wolters Kluwer Health/Lippincott Williams \& Wilkins.

3. Hassel A, Nordfjærn T, Hagen R (2013) Psychological and interpersonal distress among patients with substance use disorders: Are these factors associated with continued drug use and do they change during treatment? Journal of Substance Use 18: 363-376.

4. Mallorquí-Bagué N, Fagundo A B, Jimenez-Murcia S, De la Torre R, Baños RM, et al. (2016) Decision Making Impairment: A Shared Vulnerability in Obesity, Gambling Disorder and Substance Use Disorders? Plos One 11: e0163901. [Crossref]

5. Nordfjærn T (2011) Do severity levels of substance use relate to self-reported variations in psychosocial distress? Journal of Substance Use 16: 422-438.

6. Mohr WK, Mohr WK (2009) Psychiatric Mental Health Nursing: Evidence-based Concepts, Skills, and Practices: Wolters Kluwer Health/Lippincott Williams \& Wilkins.

7. Jones CM, Logan J, Gladden RM, Bohm MK (2015) Vital signs: demographic and substance use trends among heroin users-United States, 2002-2013. MMWR. Morbidity and mortality weekly report 64: 719-725.

8. Poudel A, Sharma C, Gautam S, Poudel A (2016) Psychosocial problems among individuals with substance use disorders in drug rehabilitation centers, Nepal. Substance abuse treatment, prevention, and policy 11: 28 .

9. Ali AA (2014) Psychosocial Determinants of Alcohol and Drug Abuse. Dirasat: Human \& Social Sciences p. 41.

10. Alzahrani TA, Abaalkhail BA, Ramadan IK (2016) Prevalence of intimate partner violence and its associated risk factors among Saudi female patients attending the primary healthcare centers in Western Saudi Arabia. Saudi Medi J 37: 96-99. [Crossref]

11. Nordfjærn T (2011) Relapse patterns among patients with substance use disorders. Journal of Substance Use 16: 313-329.
12. Caballero FF, Soulis G, Engchuan W, Sánchez-Niubó A, Arndt H, et al. (2017) Advanced analytical methodologies for measuring healthy ageing and its determinants, using factor analysis and machine learning techniques: the ATHLOS project. Sci Rep 7: 43955. [Crossref]

13. Alinsaif A (2012) A study of psychosocial factors influencing alcohol use among Saudi Arabians.

14. Armstrong G, Nuken A, Samson L, Singh S, Jorm AF, et al. (2013) Quality of life, depression, anxiety and suicidal ideation among men who inject drugs in Delhi, India. BMC Psychiatry 13: 151

15. Tiziana F, Cristiana M, Barbara C, Mara S, Vincenzo V, et al. (2014) Substance use disorders in hospitalized psychiatric patients: the experience of one psychiatric emergency service in Turin. Compr Psychiatry 55: 1234-1243. [Crossref]

16. Arteaga A, Fernández-Montalvo J, López-Goñi JJ (2015) Prevalence and differentia profile of patients with drug addiction problems who commit intimate partner violence. Am J Addict 24: 756-764. [Crossref]

17. Alzahrani H, Barton P, Brijnath B (2015) Self-reported depression and its associated factors among male inpatients admitted for substance use disorders in Saudi Arabia. Journal of Substance Use 20: 347-353.

18. Youssef IM, Fahmy MT, Haggag WL, Mohamed KA, Baalash AA (2016) Dua Diagnosis and Suicide Probability in Poly-Drug Users. J Coll Physicians Surg Pak 26: 130-133. [Crossref]

19. Al Ghaferi H, Bond C, Matheson C (2017) Does the biopsychosocial-spiritual model of addiction apply in an Islamic context? A qualitative study of Jordanian addicts in treatment. Drug Alcohol Depend 172: 14-20. [Crossref]

20. Field A (2009) Discovering statistics using SPSS: Sage publications.

21. Stevens J (2009) Applied multivariate statistics for the social sciences: Taylor \& Francis US.

22. Tabachnick BG, Fidell LS, Osterlind SJ (2001) Using multivariate statistics.

23. Cohen J (1992) A power primer. Psychol Bull 112: 155-159. [Crossref]

24. Bolton JM, Robinson J, Sareen J (2009) Self-medication of mood disorders with alcohol and drugs in the National Epidemiologic Survey on Alcohol and Related Conditions. $J$ Affect Disord 115: 367-375. [Crossref]

25. Al-Kandari FH, Yacoub K, Omu FE (2007) Effect of drug addiction on the biopsychosocial aspects of persons with addiction in Kuwait: nursing implications. Journal of Addictions Nursing 18: 31-40.

26. Kavas AB (2009) Self-esteem and health-risk behaviors among Turkish late adolescents. Adolescence 44: 187-198. [Crossref]

Copyright: (C2019 Hasan AA. This is an open-access article distributed under the terms of the Creative Commons Attribution License, which permits unrestricted use, distribution, and reproduction in any medium, provided the original author and source are credited. 